\title{
Hydrophobic Coatings Composed by Cubic-Shaped CdO Nanoparticles Grown by a Novel and Simple Microwave Method
}

\author{
Mehrdad Rashidzadeh, ${ }^{1}$ Guillermo Carbajal-Franco, ${ }^{2}$ and Arturo Tiburcio-Silver ${ }^{3}$ \\ ${ }^{1}$ Institute of Material Engineering, Islamic Azad University of Najafabad, Najafabad, Isfahan 85141-43131, Iran \\ ${ }^{2}$ Division of Graduate Studies and Research, Instituto Tecnológico de Toluca, Avenida Tecnológico, s/n, Colonia Agrícola Buenavista, \\ 52149 Metepec, MEX, Mexico \\ ${ }^{3}$ Apartado Postal 20, 52176 Metepec 3, MEX, Mexico
}

Correspondence should be addressed to Guillermo Carbajal-Franco; gcarbajal@ittoluca.edu.mx

Received 30 October 2015; Accepted 16 December 2015

Academic Editor: Ipsita Banerjee

Copyright (C) 2016 Mehrdad Rashidzadeh et al. This is an open access article distributed under the Creative Commons Attribution License, which permits unrestricted use, distribution, and reproduction in any medium, provided the original work is properly cited.

Cube-shaped cadmium oxide $(\mathrm{CdO})$ nanoparticles were deposited by a novel low cost microwave evaporation technique. High purity cadmium $(\mathrm{Cd})$ flakes were placed in a microwave susceptor inside a commercial microwave oven. Metallic Cd was evaporated in less than 2 minutes and it was oxidized due to ambient oxygen. The CdO nanoparticles were deposited on a glass substrate placed few centimeters above the susceptor. The surfaces with nanoparticles were treated with a solution containing ethanol and phenyltriethoxysilane (PTES), and the hydrophobic properties of the as-synthesized and post-PTES-treated surfaces were studied. Morphological and structural information of the as-synthesized nanoparticles were investigated via SEM and XRD analysis. Contact angles $\left(\theta_{C}\right)$ for the as-synthesized CdO surfaces were about $112^{\circ}$, whereas, for ethanol/PTES-treated CdO nanoparticles surfaces, contact angles were improved to about $158^{\circ}$. Thus, ethanol/PTES-treated CdO nanoparticles obtained by this simple procedure showed superhydrophobicity properties of potential use in micro fluidic devices and some other applications in the future.

\section{Introduction}

Lotus effect is a subject that has attracted the interest of many researchers. It refers to the high water repellence resulting in self-cleaning properties as exhibited by the leaves of the lotus flower $[1,2]$. Thus, from the technological point of view, it would be useful to improve this ability on a range of materials to be used in different applications. Some of these applications would have a direct effect on our life. For example, hydrophobic glass windows are the most useable products that make use of the lotus effect. Wettability, directly related to hydrophobicity, of solid surfaces is governed by chemical composition and geometric structure of the surface. Hydrophobicity can be characterized by measuring the contact angle $\left(\theta_{C}\right)$, which is measured at the triple-energy point where the liquid, solid, and gas phases interact. Depending on its value, the surface can be classified in one of three different categories: hydrophilic $\left(\theta_{C} \leq 90^{\circ}\right)$, hydrophobic $\left(90^{\circ}<\theta_{C} \leq\right.$ $\left.150^{\circ}\right)$, and superhydrophobic $\left(\theta_{C}>150^{\circ}\right)$. The angle $\theta_{C}$ can be changed, for example, by applying sealants to the surface; fluorinated polymers or additives are typically used for this matter. Cleaning procedures based on high contact angles are known since the invention of soap (3rd millennium BC) [3]; generally speaking, detergents reduce the surface tension of water and the contact angle will increase. Another very interesting possibility to cause large contact angles without detergents is the use of micro/nanostructured coatings on the surface of the material of interest $[1,2,4]$. It is also possible to increase the hydrophobic properties of a surface by the use of active materials on it. Metal oxides or sulfides $[5,6]$ have been applied for this matter; and one of these metal oxides is cadmium oxide [7].

Cadmium oxide has been fabricated on solid surfaces via different methods such as sol-gel $[8,9]$, successive ionic layer adsorption and reaction (SILAR) [10, 11], thermal evaporation [12-14], PEG-assisted route [15], among others. Superhydrophobic conductive zinc oxide thin films with great practical and potential applications like micro fluidic devices 
have been prepared by Li et al. [16]. All of these methods have some advantages, but they also exhibit some inconveniences among which we can mention high cost of production due to the complex equipment used for deposition, long processing time, low growth rate, and long time for production. In this regard, microwave-heating under ambient conditions is a relatively new technique for fast and direct cadmium oxide synthesis, which is different from existing conventional process. This new method is very simple and fast and is able to produce both, nanopowders and thin films. For increased thickness of thin films or larger nanopowder quantity, the process can be repeated as many times as needed. To our knowledge, this is the first time that cadmium oxide is prepared following the microwave-assisted method proposed in this paper. In this work, we have deposited nanoparticulated $\mathrm{CdO}$ coatings by the procedure previously described in order to study its hydrophobic properties.

\section{Materials and Methods}

2.1. Materials and Structural Characterization. All reagents were commercial grade and were used without further purification. Pure silicon carbide powder (with an average grain size of about $100 \mu \mathrm{m}$ ) was used as the main microwaveheater material. Some alumina fireclay bricks were used as a thermal shield. High purity cadmium metal (up to $99.9 \%$ ) was used as raw material and a domestic microwave oven (brand: LG, model: LF 5700 S, with $900 \mathrm{~W}$ of output power at $2.4 \mathrm{GHz}$ ) was used as heater. An electric oven (Exciton 1500) was used for thermal treatments. Ethanol from Merck was used in all experiments. Some $\mathrm{CdO}$ depositions were heat-treated for $1 \mathrm{hr} 15 \mathrm{~min}$ at $450^{\circ} \mathrm{C}$ for investigation of the annealing effect on the hydrophobicity of the samples. XRD patterns were obtained with a PHILIPS PW3040 diffractometer $(\mathrm{CuK} \alpha$ source with $\mathrm{Ni}$ filter, wavelength $\lambda=1.5405 \AA$ ). All FESEM images were obtained with a TESCAN VEGA MIRA3 scanning electron microscope.

2.2. Nanoparticle Synthesis. First of all, it was required to elaborate a crucible capable of operating under microwave heating and withstand high temperatures. For this matter, silicon carbide powder, some additive oxides (iron oxide and alumina), and sufficient water to obtain a malleable mixture were used to fabricate a cylinder by cold press process. A small hole was made on one of the flat surfaces of the cylinder, to finish the vessel by heat treatment at $450^{\circ} \mathrm{C}$ in an electrical oven. The temperature of the susceptor increases up to $1200^{\circ} \mathrm{C}$ in less than 60 seconds when it is exposed to microwave radiation. For the $\mathrm{CdO}$ coating deposition, a small amount of metallic flakes of cadmium was placed inside the crucible and the microwave oven was turned on for 2 minutes. When the heater temperature reached about $1200^{\circ} \mathrm{C}$, a massive evaporation of cadmium occurs. On its travel, the Cd vapor reacted with oxygen atoms of the ambient air and was deposited in the form of cadmium oxide nanoparticles on the surface of the glass substrate that was placed a few centimeters above the crucible at ambient temperature. The total duration of the experiment was less than $2 \mathrm{~min}$. These cadmium oxide nanoparticles can be easily applied to other

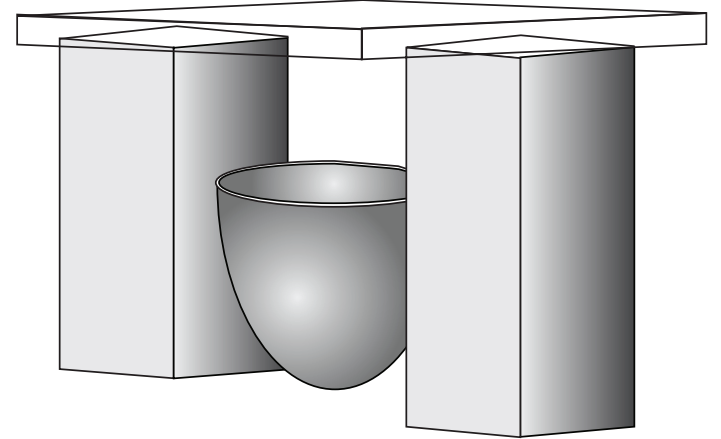

FIGURE 1: A schematic diagram of the system setup for the synthesis of CdO nanoparticles.

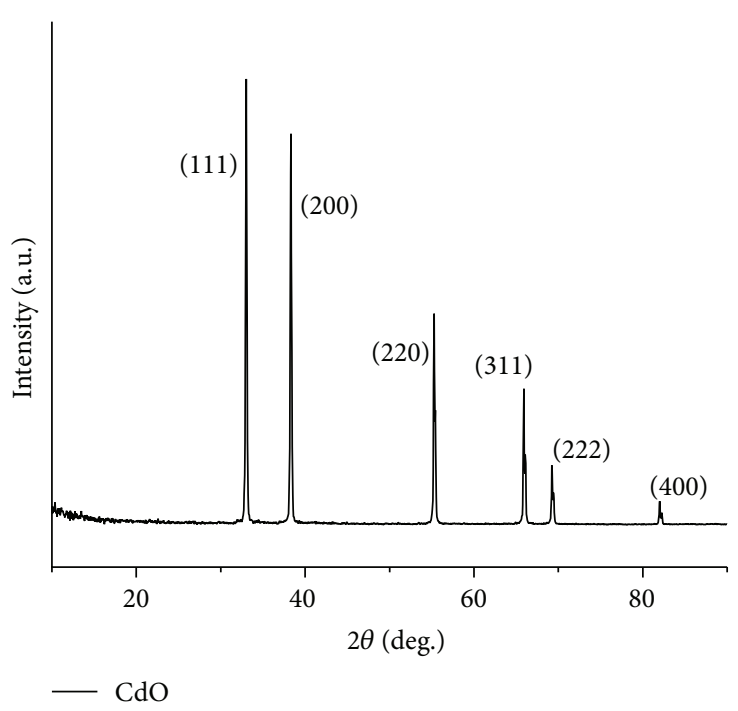

FIGURE 2: X-ray diffraction spectrum of as-synthesized CdO nanoparticles.

substrates such as bricks, metals, and polymers. Figure 1 shows a schematic diagram of the setup system for the synthesis of CdO nanoparticles.

2.3. Hydrophobic Surface Treatment. As-synthesized nanoparticles were treated by a hydrophobic solution containing phenyltriethoxysilane (PTES) and ethanol as solvent. This solution was applied to the CdO-treated glass substrates by spraying or pouring drops of the solution onto the surface allowing the solvent to be evaporated, and without any further treatment. Different samples were prepared with various ethanol and PTES quantities to investigate the effect of the ethanol/PTES ratio on hydrophobicity.

\section{Results and Discussion}

3.1. CdO Coatings Structural Characterization. Figure 2 shows an indexed (PDF: 5-0640) XRD pattern of the as-synthesized $\mathrm{CdO}$ nanoparticles. As it can be seen, well-crystallized and pure $\mathrm{CdO}$ nanoparticles were obtained. 


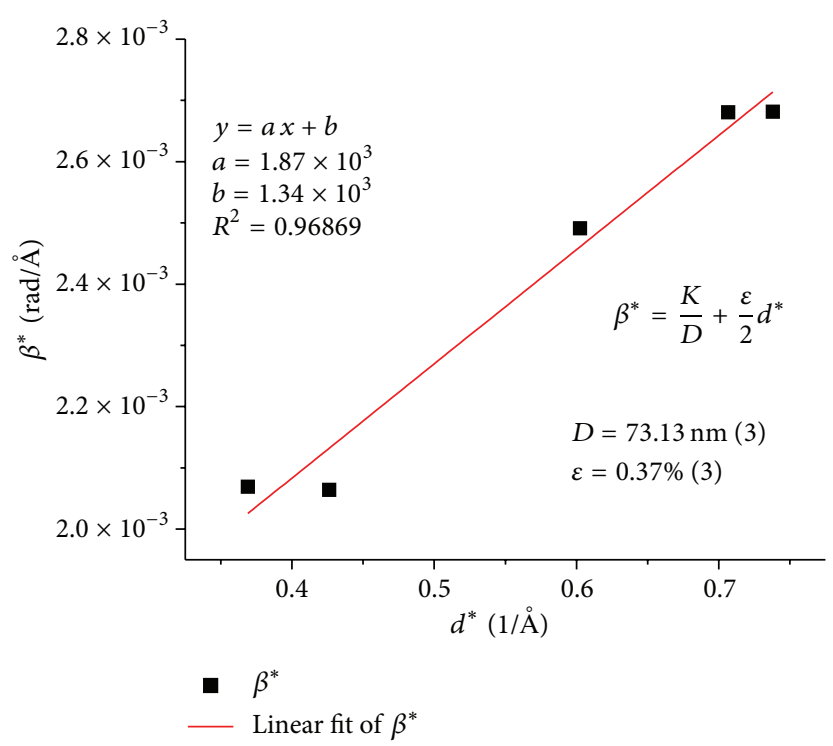

Figure 3: W-H plot diagram.

The average crystallite grains size $(D)$ and strain $(\varepsilon)$ were determined by using the Williamson-Hall (W-H) formulation, under the Uniform Deformation Model (UDM) approach, where the isotropic nature of the crystal is considered [17]. This is a valid assumption as CdO crystallizes in a face-center cubic structure that is isotropic, and our nanoparticles are not under particular strain effects like it is the case in thin films [18]. The basis of the analysis considers that the XRD peak breadth is the sum of the breadth due to crystallite size (Scherrer considerations) and strain effects. The former varies with respect to $1 / \cos \theta$ and the latter varies with respect to $\tan \theta$ (with $\theta$ being the Bragg angle). In this way, a linear fit can be used to relate the line breath, $\beta_{2 \theta}$, to the mean crystallite size, $D$, and the strain, $\varepsilon$ [17-19]:

$$
\beta_{2 \theta}=\frac{K \lambda}{D \cos \theta}+4 \varepsilon \tan \theta
$$

where $K$ is the Scherrer constant (in this work, 0.98 was used but can be set from 0.62 to 2.08 depending on some characteristics of the material under analysis [20]) and $\lambda$ is the $\mathrm{X}$-ray wavelength. Equation (1) can be simplified by defining

$$
\begin{aligned}
& \beta^{*}=\frac{\beta_{2 \theta} \cos \theta}{\lambda}, \\
& d^{*}=\frac{2 \sin \theta}{\lambda} .
\end{aligned}
$$

Giving

$$
\beta^{*}=\frac{K}{D}+\frac{\varepsilon}{2} d^{*}
$$

By plotting $d^{*}$ along the $x$-axis and $\beta^{*}$ along the $y$-axis, we obtain what is called a W-H plot diagram. From the linear fit to the data, the crystallite size, $D$, can be estimated from the $y$-intercept and the strain, $\varepsilon$, from the slope of the fit.
Our results are shown in Figure 3

FE-SEM images of the as-synthesized CdO nanoparticles are displayed in Figures 4(a) and 4(b). The cube-shaped structure of the nanoparticles is evident with sharp edges that are still well defined even at high magnification (Figure 4(b)).

Figures 5(a) and 5(b) show images at different magnifications of the samples after a one hour fifteen minutes of heat treatment at $450^{\circ} \mathrm{C}$.

From the FE-SEM image of the heat-treated sample (Figures 5(a) and 5(b)), the loosing of the sharp edges and corners of the nanocubes is evident, resulting in larger polyhedral structures. This phenomenon is due to the minimization of the surface energy, driven by the relatively high temperature of the heat treatment (one-half of the melting point approximately). This behavior could be seen as a mixture of sintering and Ostwald ripening [21], which can be reached at temperatures as low as half of the melting-point temperature, leading to more energy-stable structures that are in accordance with the Wulff constructions [22].

3.2. Hydrophobicity of the Coatings. A standard droplet of water was deposited on the surface of the glass substrate with the as-synthesized $\mathrm{CdO}$ nanoparticles and to the substrate with nanoparticles treated with the PTES/ethanol hydrophobic solution. Contact angles were measured with Image J [23] and the plug-in written by Stalder et al. [24]. Figure 6 shows the water-drop images of the most representative samples and the left and right measured angles. Table 1 presents the contact angles observed for these surfaces.

From Table 1, it can be seen that the as-synthesized coatings have a larger contact angle because of their higher surface to volume ratio and that the annealing treatment decreased the contact angle and lotus effect. This reduction of the hydrophobic properties of the coating is attributed to the losing of the cubic shape of the nanostructures, and 


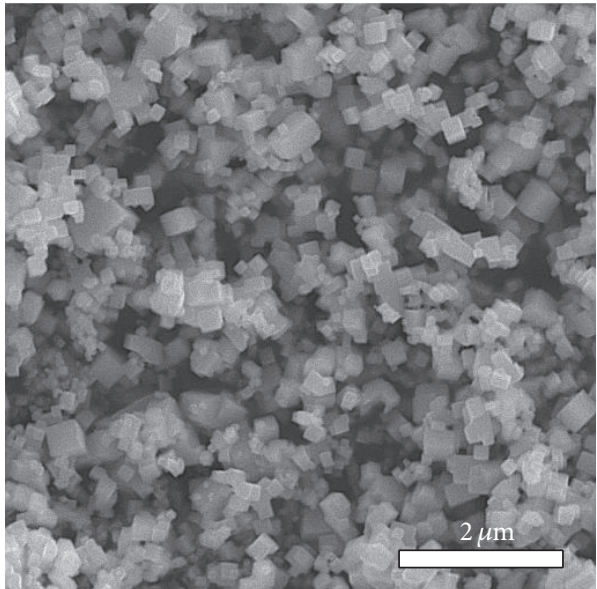

(a)

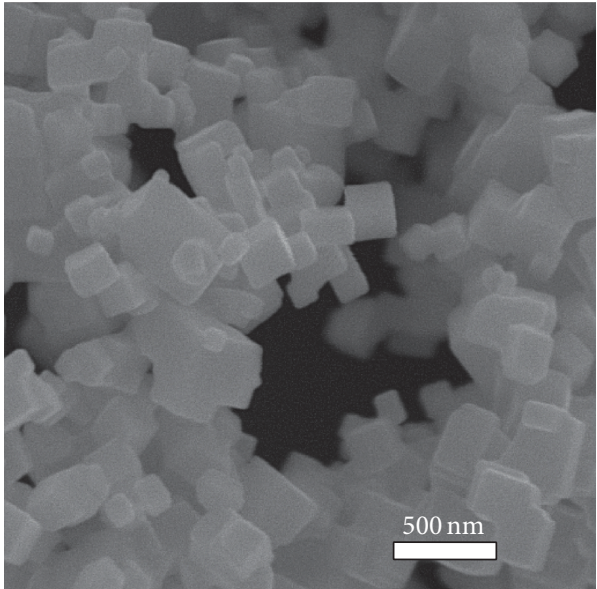

(b)

FIGURE 4: FE-SEM images of as-synthesized CdO nanoparticles at different magnifications.

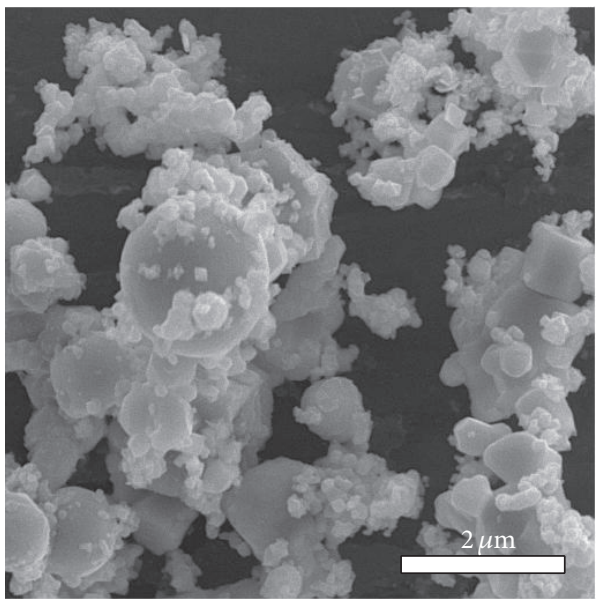

(a)

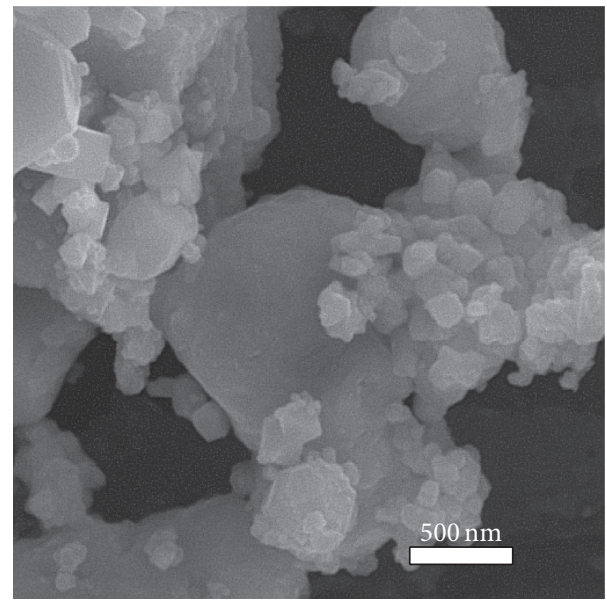

(b)

FIGURE 5: FE-SEM images of CdO samples after annealing for $1 \mathrm{hr}$ and $15 \mathrm{~min}$ at $450^{\circ} \mathrm{C}$.

the asymmetry exhibited by the angles is attributed to the irregular distribution of the sintered nanoparticles on the surface; smaller angle indicates larger particles or the absence of a nanostructured motif on the surface of the substrate. Based on this analysis, we conclude that the as-synthesized samples follow the Wenzel and Cassie-Baxter models; meanwhile, heat-treated samples are closer to the Young model $[1,4]$. Coatings that were subject of ethanol: PTES treatment exhibit a larger contact angle because of the change of the surface energy induced by the PTES, and it is increased by decreasing ethanol: PTES ratio. Other changes in ethanol or PTES quantities have no positive effect on contact angle.

\section{Conclusion}

Nanoparticulated cube-shaped cadmium oxide coatings were synthesized via direct, fast, and simple microwave method.
Different thicknesses can be achieved by increasing the amount of raw material or by repeating the process as required to obtain a fixed thickness. This procedure can be used to deposit coatings on glass, bricks, and other types of substrates. As-synthesized coatings were composed by cubicshaped nanostructures and had a good crystallinity not showing any metallic traces. They presented an average crystallite size of $D=73 \mathrm{~nm}$ and a strain of $\varepsilon=0.37 \%$, and hydrophobic properties. Annealed thin films were not hydrophobic due to sintering/Ostwald ripening effects. Ethanol: PTES-treated thin films were superhydrophobic and contact angel varies with different ethanol and PTES concentration, being the 12:1 ethanol: PTES ratio, the one which impaired the higher contact angle on the nanostructured $\mathrm{CdO}$ coatings. This new method solves some problems of other procedures and decreases the $\mathrm{CdO}$ coating deposition time (less than 2 minutes). These $\mathrm{CdO}$ coatings can be used to produce 


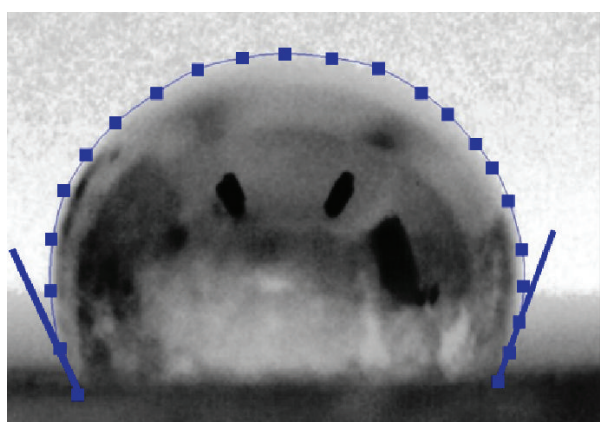

(a)

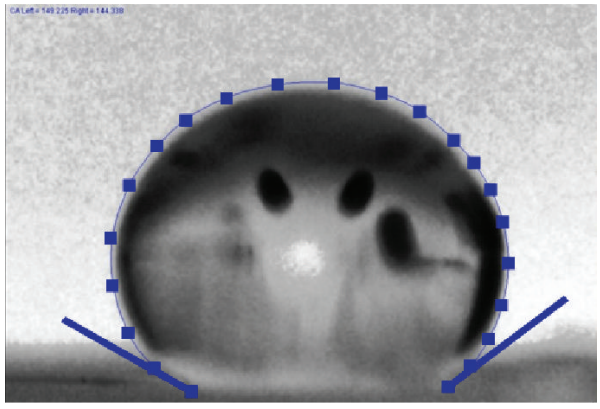

(c)

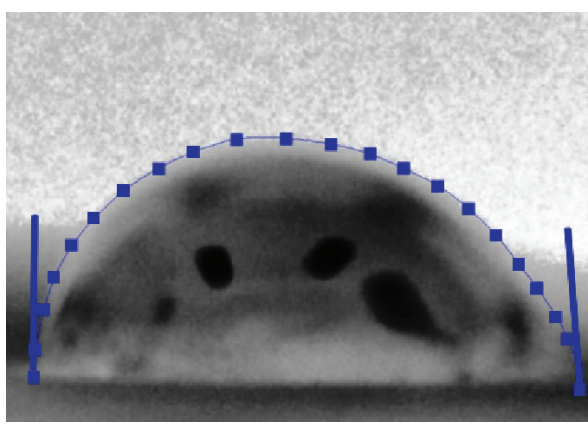

(b)

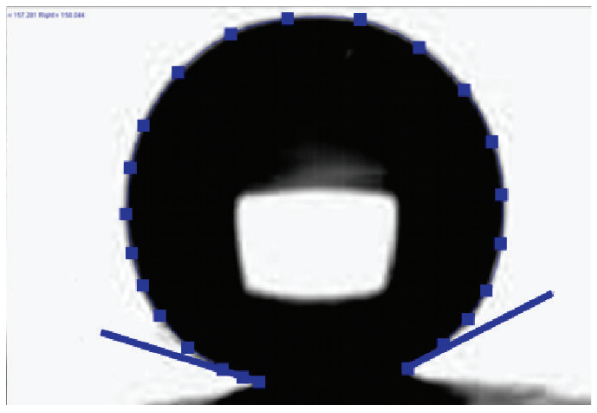

(d)

FiguRE 6: Drop images analyzed for angle measurement. (a) As-synthesized nanoparticles, (b) annealed nanoparticles, (c) 20:1 ethanol: PTES-treated nanoparticles, and (d) 12:1 ethanol: PTES-treated nanoparticles.

TABLE 1: Contact angles of coated surfaces for several concentrations of the hydrophobic solution.

\begin{tabular}{|c|c|c|c|c|}
\hline \multirow{2}{*}{ Coating type } & \multicolumn{2}{|c|}{ Contact angles $\left({ }^{\circ}\right)$} & \multirow{2}{*}{ Ethanol: PTES ratio } & \multirow{2}{*}{ Figure } \\
\hline & Left & Right & & \\
\hline As-synthesized nanoparticles & 113 & 112 & - & Figure 6(a) \\
\hline Annealed nanoparticles & 91 & 84 & - & Figure 6(b) \\
\hline PTES-treated nanoparticles & 149 & 144 & $100: 1$ & Not shown \\
\hline PTES-treated nanoparticles & 156 & 152 & $20: 1$ & Figure $6(c)$ \\
\hline PTES-treated nanoparticles & 157 & 158 & $12: 1$ & Figure $6(\mathrm{~d})$ \\
\hline
\end{tabular}

conductive thin films for transparent electrodes, micro fluidic devices among other interesting applications in the future.

\section{Conflict of Interests}

The authors declare that there is no conflict of interests regarding the publication of this paper.

\section{References}

[1] Y. Y. Yan, N. Gao, and W. Barthlott, "Mimicking natural superhydrophobic surfaces and grasping the wetting process: a review on recent progress in preparing superhydrophobic surfaces," Advances in Colloid and Interface Science, vol. 169, no. 2, pp. 80-105, 2011.

[2] M. Ma and R. M. Hill, "Superhydrophobic surfaces," Current Opinion in Colloid \& Interface Science, vol. 11, no. 4, pp. 193-202, 2006.
[3] Z. Goffer, Archeological Chemistry, John Wiley \& Sons, Hoboken, NJ, USA, 2nd edition, 2007.

[4] E. Celia, T. Darmanin, E. T. de Givenchy, S. Amigoni, and F. Guittard, "Recent advances in designing superhydrophobic surfaces," Journal of Colloid and Interface Science, vol. 402, pp. 1-18, 2013.

[5] V. R. Shinde, C. D. Lokhande, R. S. Mane, and S.-H. Han, "Hydrophobic and textured $\mathrm{ZnO}$ films deposited by chemical bath deposition: annealing effect," Applied Surface Science, vol. 245, no. 1-4, pp. 407-413, 2005.

[6] Z. Gao, X. Zhai, F. Liu, M. Zhang, D. Zang, and C. Wang, "Fabrication of $\mathrm{TiO}_{2} / \mathrm{EP}$ super-hydrophobic thin film on filter paper surface," Carbohydrate Polymers, vol. 128, pp. 24-31, 2015.

[7] K. Sankarasubramanian, P. Soundarrajan, K. Sethuraman, R. R. Babu, and K. Ramamurthi, "Structural, optical and electrical properties of transparent conducting hydrophobic cadmium oxide thin films prepared by spray pyrolysis technique," Superlattices and Microstructures, vol. 69, pp. 29-37, 2014. 
[8] M. Benhaliliba, C. E. Benouis, A. Tiburcio-Silver et al., "Luminescence and physical properties of copper doped CdO derived nanostructures," Journal of Luminescence, vol. 132, no. 10, pp. 2653-2658, 2012.

[9] S. Aksoy and Y. Caglar, "Electrical properties of n-CdO/p-Si heterojunction diode fabricated by sol gel," World Academy of Science, Engineering and Technology, vol. 59, pp. 2113-2116, 2011.

[10] R. R. Salunkhe and C. D. Lokhande, "Effect of film thickness on liquefied petroleum gas (LPG) sensing properties of SILAR deposited CdO thin films," Sensors and Actuators B: Chemical, vol. 129, no. 1, pp. 345-351, 2008.

[11] M. H. Suhail, I. M. Ibrahim, and G. M. Rao, "Characterization and gas sensitivity of cadmium oxide thin films prepared by thermal evaporation technique," Journal of Electron Devices, vol. 13, pp. 965-974, 2012.

[12] R. S. Rusu and G. I. Rusu, "On the electrical and optical characteristics of CdO thin films," Journal of Optoelectronics and Advanced Materials, vol. 7, no. 3, pp. 1511-1516, 2005.

[13] T.-J. Kuo and M. H. Huang, "Gold-catalyzed low-temperature growth of cadmium oxide nanowires by vapor transport," The Journal of Physical Chemistry B, vol. 110, no. 28, pp. 13717-13721, 2006.

[14] M. Zaien, N. M. Ahmed, and Z. Hassan, "Growth of cadmium oxide nanorods by vapor transport," Chalcogenide Letters, vol. 9, no. 3, pp. 115-119, 2012.

[15] M. Lashanizadegan and H. Mirzazadeh, "Synthesis of Cd $(\mathrm{OH})_{2}$ and CdO nanoparticles via a PEG-assisted route," Journal of Ceramic Processing Research, vol. 13, no. 4, pp. 389-391, 2012.

[16] M. Li, J. Zhai, H. Liu, Y. Song, L. Jiang, and D. Zhu, "Electrochemical deposition of conductive superhydrophobic zinc oxide thin films," Journal of Physical Chemistry B, vol. 107, no. 37, pp. 9954-9957, 2003.

[17] A. Khorsand Zak, W. H. Abd Majid, M. E. Abrishami, and R. Yousefi, "X-ray analysis of $\mathrm{ZnO}$ nanoparticles by WilliamsonHall and size-strain plot methods," Solid State Sciences, vol. 13, no. 1, pp. 251-256, 2011.

[18] V. D. Mote, Y. Purushotham, and B. N. Dole, "WilliamsonHall analysis in estimation of lattice strain in nanometer-sized ZnO particles," Journal of Theoretical and Applied Physics, vol. 6, article 6, 8 pages, 2012.

[19] R. Guinebretière, X-Ray Diffraction by Polycrystalline Materials, ISTE, Newport Beach, Calif, USA, 1st edition, 2007.

[20] V. Uvarov and I. Popov, "Metrological characterization of X-ray diffraction methods at different acquisition geometries for determination of crystallite size in nano-scale materials," Materials Characterization, vol. 85, pp. 111-123, 2013.

[21] T. W. Hansen, A. T. Delariva, S. R. Challa, and A. K. Datye, "Sintering of catalytic nanoparticles: particle migration or ostwald ripening?" Accounts of Chemical Research, vol. 46, no. 8, pp. 1720-1730, 2013.

[22] L. Crosby, J. Enterkin, F. Rabuffetti, K. Poeppelmeier, and L. Marks, "Wulff shape of strontium titanate nanocuboids," Surface Science, vol. 632, pp. L22-L25, 2015.

[23] M. D. Abramoff, P. J. Magalhaes, and S. J. Ram, "Image processing with Image), Biophotonics International, vol. 11, no. 7, pp. 36-42, 2004.

[24] A. F. Stalder, G. Kulik, D. Sage, L. Barbieri, and P. Hoffmann, "A snake-based approach to accurate determination of both contact points and contact angles," Colloids and Surfaces A: Physicochemical and Engineering Aspects, vol. 286, no. 1-3, pp. 92-103, 2006. 

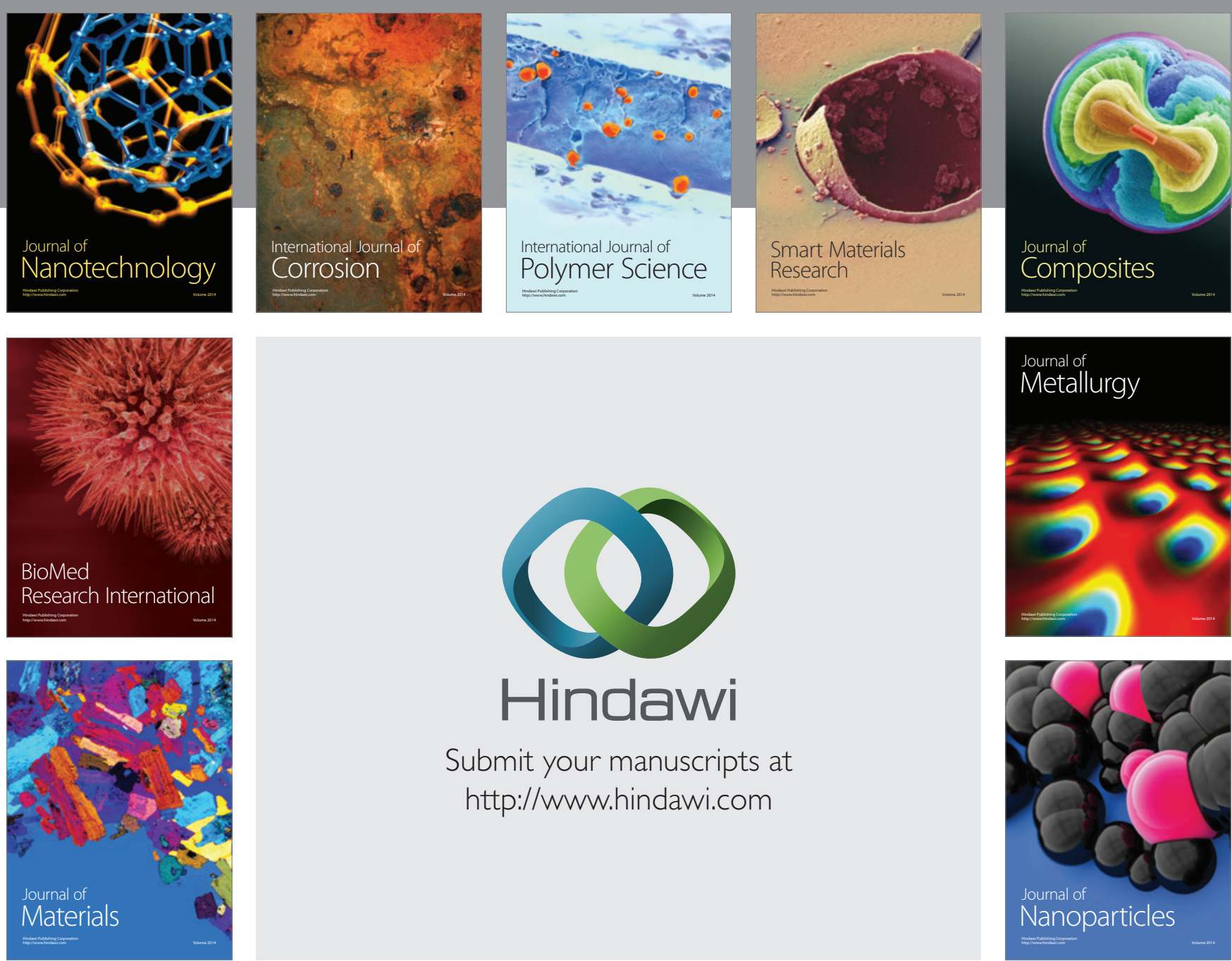

\section{Hindawi}

Submit your manuscripts at

http://www.hindawi.com

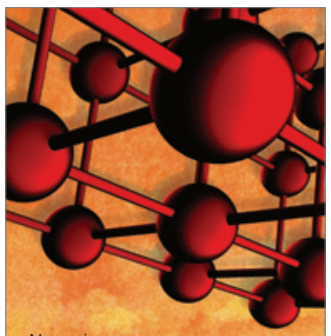

Materials Science and Engineering
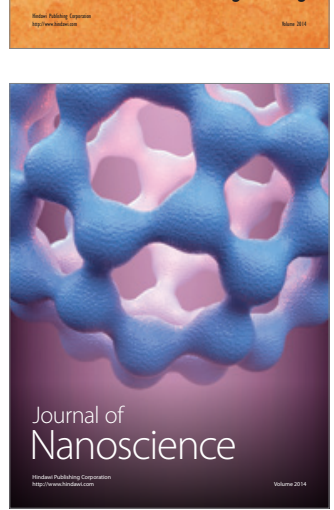
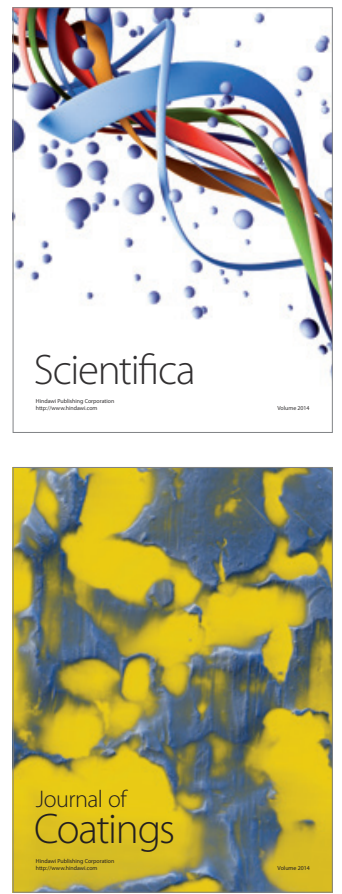
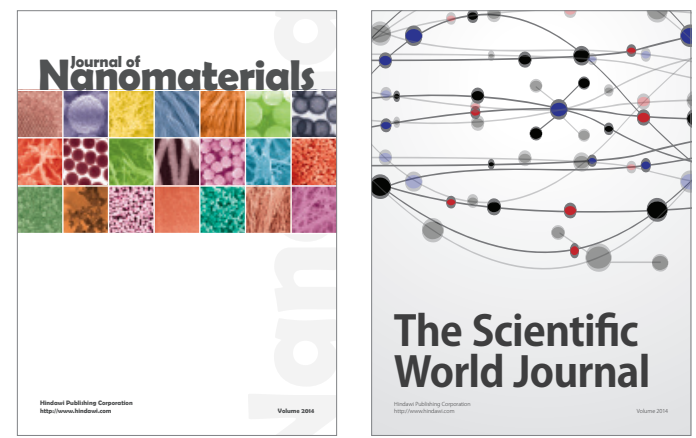

The Scientific World Journal
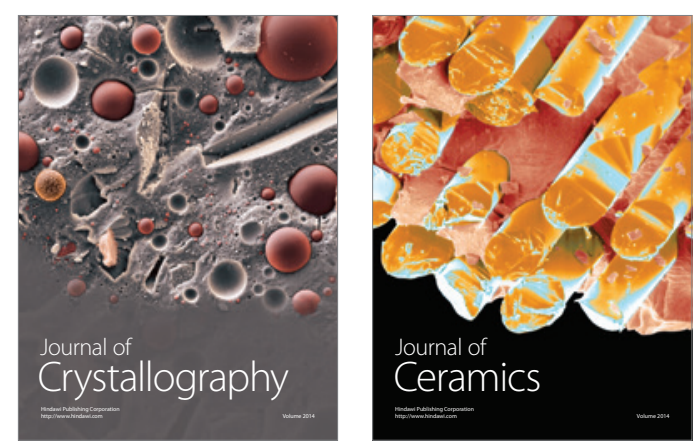
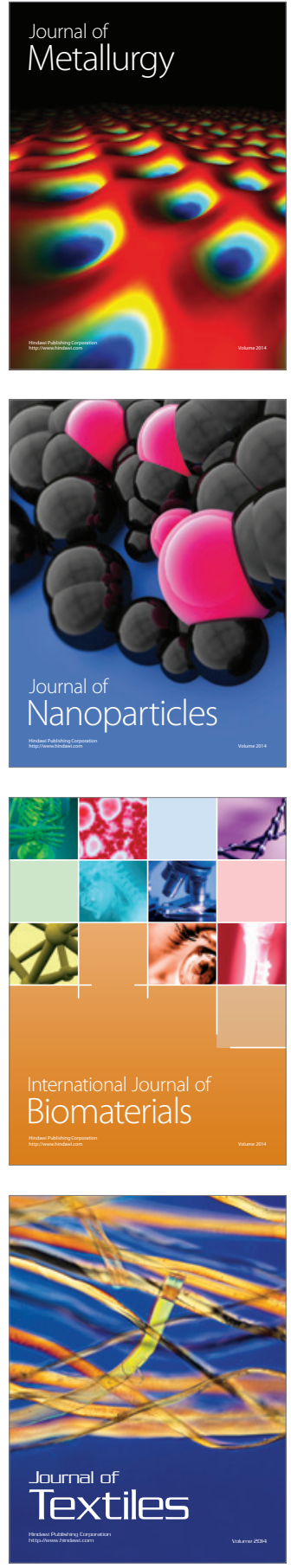